\title{
Agricultural Spray Inspection According to ISO 16122
}

\author{
Alfran Tellechea Martini ${ }^{1}$, José Fernando Schlosser ${ }^{1}$, Emilio Gil ${ }^{2}$, Marcelo Silveira de Farias ${ }^{1}$, \\ Gilvan Moisés Bertollo ${ }^{1}$, Luis Fernando Vargas de Oliveira ${ }^{1} \&$ Giácomo Müller Negri ${ }^{1}$ \\ ${ }^{1}$ Department of Rural Engineering, Universidade Federal de Santa Maria, Campus Universitário, Santa Maria, \\ Brazil \\ ${ }^{2}$ Unidad de Mecanización Agraria, Universitat Politècnica de Catalunya, Barcelona, Spain \\ Correspondence: Alfran Tellechea Martini, Department of Rural Engineering, Universidade Federal de Santa \\ Maria, 1000 Ave. Roraima, Campus Universitário, Santa Maria, Brazil. Tel: 55-559-9975-4356. E-mail: \\ alfrantm@gmail.com
}

Received: November 28, 2018

Accepted: January 4, 2019

Online Published: March 15, 2019

doi:10.5539/jas.v11n4p60

URL: https://doi.org/10.5539/jas.v11n4p60

\begin{abstract}
The development of the primary sector by expansion of cultivation areas and the raise of productive indexes promotes a larger use of agrotoxics, causing problems related to the inefficiency of applications, which becomes an issue to be studied, especially regarding the quality of sprayers and the precision of spraying. The goal of the present paper is to determine the condition and conservation of agricultural sprayers used in the West border and the Central region of Rio Grande do Sul state (RS), in southern Brazil, as well as identifying the most recurring problems, and assessing the applicability of ISO 16122 in the country's reality. The execution of this work originated the Projeto de Inspeção de Pulverizadores Agrícolas (PIPA) [Agricultural Sprayer Inspection Project], which was undertaken in two regions of RS, inspecting 56 sprayers. The inspections were carried out by using the technical kit for agricultural sprayer inspection, according to requirements in the methodology described in ISO 16122 (2015). After evaluations were conducted, the data collected were submitted to exploratory analysis by descriptive statistics with the use of percentage frequency. Based on the results obtained, it was possible to conclude that there is need for agricultural sprayer inspection to become mandatory in Brazil. Considering the most frequent application problems, it was possible to verify that, in $64.29 \%$ of the evaluations, the precision of the manometer was considered as seriously flawed; in $73.21 \%$, the transverse distribution of the spray wand was also seriously flawed, which is related principally to errors in the space among spray nozzles, and to their wear, affecting $76.79 \%$ of the cases in terms of application volume. Besides these, it was also observed that, in $69.64 \%$ of the inspected sprayers, the PTO rotation was below recommendation. In relation to the applicability of ISO 16122 , it was concluded that there is need for it to be updated, developing specific methodologies for the inspection of self-propelled sprayers. In this sense, in case it be transcribed as ABNT NBR ISO 16122, the latter must specify new parameters so it be unanimously and appropriately used in accordance to Brazilian reality.
\end{abstract}

Keywords: technical Inspection, agricultural sprayers, condition and conservation

\section{Introduction}

In the world context of agrotoxic utilization, despite the high efficiency of the currently available products, their deposition, by means of current application methods, shows little efficiency, given that sometimes the best application techniques or equipment are not used (Martini et al., 2016b).

The effectiveness of spraying is influenced by several factors, such as weather conditions, equipment and structural features of the plants. In this sense, it was observed that, in aerial spraying, for example, while evaluating different equipment and application volumes, Martini et al. (2016a) highlights that, according to the equipment used, there were differences in the concentration of the deposited product in the range of application. Based on their studies, losses range from 27.80 to $93.76 \%$ when cone spray nozzles are used, with and without electric charge induction on the droplet, respectively.

In an attempt to improve agrotoxic application efficiency, studies are being developed so as to increase deposition onto targets, reduce losses and environmental contamination. In order to do this, the spraying nozzles used in agricultural sprayers must fraction the solution into droplets by a physical process, and distribute them uniformly along the target, so as to optimize its effect. This demand is being reached by application equipment 
improvement; however, it may be observed that the new technology produced by R\&D is more slowly transferred to agricultural areas.

It is, therefore, important to focus on the maintenance of agricultural sprayers, so the equipment may function efficiently, which shall have direct impact on profits (Lanças \& Antuniassi, 1998). These authors also claim that agricultural sprayer inspection is the most important part of preventive maintenance, since it enables the assessment of the real operational conditions of sprayers, and often the reduction of time in applying corrective measures.

In Germany, the development of the first sprayer inspection projects began in the 1960s, voluntarily evaluating wand sprayers; in 1969, inspection of sprayers in use began in Italy. According to Ganzelmeier (2007), in the mid-1980s, turbo atomizer sprayers and air-assisted sprayers inspections began in Germany. However, due to low engagement of producers, in 1993, inspection became mandatory for wand sprayers and, in 2002, for turbo atomizers and air-assisted sprayers. After inspection became mandatory in Germany, Koch (1996) developed an evaluation methodology, split into qualitative and quantitative stages. Qualitative assessment is related to the overall maintenance of strainers, protection of mobile parts and detection of leaking. Quantitative assessment is related to nozzle flow, dislocation speed and wand length.

Studies show that, with the evolution of evaluation methodology along the years, there was an improvement in the quality of applications, as well as reduction in the rejection rates of sprayers, resulting in more efficient spraying and in reduction of environmental contamination (Osteroth, 2004). With these results, and with a view to standardize the methodology, Standard EN 13790 was created in the European Union, defining methods and requirements for sprayers inspection (Declercq et al., 2009). Later, with the purpose of internationally unifying the methodology for sprayer inspection, based on this standard, the Standard ISO 16122 (2015) was created, which establishes materials and methods for sprayer inspection, referring to operational and environmental safety, to the condition and conservation of sprayers, and to agrotoxic application precision.

The goal of the present paper is to determine the condition and conservation of agricultural sprayers used in the West border and the Central region of Rio Grande do Sul state (RS), in southern Brazil, as well as identifying the most recurring problems, and evaluating the applicability of ISO 16122 in the country's reality.

\section{Materials and Methods}

The execution of this work originated the Projeto de Inspeção de Pulverizadores Agrícolas (PIPA) [Agricultural Sprayer Inspection Project], which was undertaken in two regions of RS, comprising nine municipalities. It was conducted in the West border, in the municipalities of Itaqui and Maçambará. In the central part of the state, it took place in the municipalities of Dona Francisca, Faxinal do Soturno, Ivorá, Restinga Seca, Santa Maria, São João do Polêsine, and São Pedro do Sul.

The methodology outlined in ISO 16122 (2015) was employed for sprayer inspection. This methodology is divided in four parts. Parts I and II were used and a questionnaire (Appendix A) was constructed to evaluating items related to spray tank, manometer, strainer, spraying wand, nozzles, sprayer pump in sprayers attached to the traction bars of agricultural tractors and to the three points of the hydraulic system of tractors.

For the evaluation of these items, an agricultural sprayer technical inspection kit was used, which is composed of digital calibration sensors, pressure gauges, and a bench top for manometer measurement.

\subsection{Tank Inspection}

Initially, were evaluated the closure of the tank, and the condition and conservation of the lid. Then, were evaluated the presence and legibility of the sprayer volume indicator, the presence of remains both inside and outside the tank, the presence of product incorporator and its suction opening, which should have a maximum diameter of $20 \mathrm{~mm}$, clean water tank for package pressure washing, solution tank drain valve, and water carriage non-return valve. Additionally, the presence of pressure compensator was also taken into account.

\subsection{Manometer Inspection}

It was verified the presence and type of manometer (whether analogical or digital) and its visibility; if analogical, its glycerin levels, scale and legibility. Manometers were approved as to scale if they presented a minimum scale of $19 \mathrm{kPa}(0.2 \mathrm{bar})$ for working pressure inferior to $476 \mathrm{kPa}(5.0 \mathrm{bar})$, and a minimum scale of $95.2 \mathrm{kPa}(1.0 \mathrm{bar})$ for working pressure between 476 and $1904 \mathrm{kPa}$ (5.0 and 20.0 bar). They should also be $63 \mathrm{~mm}$ in diameter.

The functionality of the pressure regulator and of the spraying valve was also evaluated. The pressure adjustment device should keep pressure constant in the system, with $\pm 10 \%$ tolerance, and should return after 10 seconds to 
working pressure, $\pm 10 \%$ after sprayer was turned off and on again. The pressure used for evaluation was 285.6 $\mathrm{kPa}(3.0$ bar).

Manometer evaluation was conducted in a bench top for manometer measurement. The manometer was attached to the bench. By means of a communicating tube, the bench connects the sprayer manometer under inspection to a high-precision calibrated manometer.

The evaluation was conducted with various pressure levels, according to the scale presented or the kind of spray nozzle used. For manometers equipped with flat fan spray nozzles, pressure levels were: 95, 190, 285, 380, 476 and $571 \mathrm{kPa}(1,2,3,4,5$ and 6 bar); for manometers equipped with cone spray nozzles (either full or hollow), pressure levels were: $95,190,285,380,476,571,666,761,856,951,1046,1141,1236,1331,1426,1521,1616$, 1711,1806 and $1901 \mathrm{kPa}(1,2,3,4,56,7,8,9,10,11,12,13,14,15,16,17,18,19$ and 20 bar), evaluated in ascending and descending order. For this item, maximum value acceptable was a $\pm 10 \%$ difference in pressure between sprayer manometer and high-precision manometer.

\subsection{Strainer Inspection}

The evaluation was conducted by visualization of the conditions for straining, observing the presence of strainers, the sprayer supply system, straying pump, solution tank, line strainers and nozzle strainers. These were removed, and observed as to the presence of remains and deterioration in the straining meshes. During inspection, the functioning of valves for washing the filters was also evaluated.

\subsection{Spray Wand Inspection}

For the evaluation of spray wands, their stability and symmetry were visually observed, the position of hoses, the presence of a safety system, height-adjustment device, external nozzle protection (mandatory for wands larger than $10 \mathrm{~m}$ length) and distance between nozzles (determined with a millimeter measuring tape), which was considered acceptable when there was a $\pm 5 \%$ deviation from standard recommendation.

As for vertical and horizontal wand uniformity, well-functioning devices for damping and stabilization were required. Wear evaluation and, consequently, evaluation of vertical and horizontal variation of the wand were measured with a millimeter measure tape. Vertical acceptable variation was $\pm 10 \mathrm{~cm}$ or $0.5 \%$ (whichever was highest) in relation to regular working height. For horizontal stabilization, maximum acceptable variation was $\pm 2.5 \%$ in relation to regular working height.

When inspecting hose conservation, this was visually done by observing its disposition in the wand, droplet deposits in structural parts of the equipment, as well as the presence of folds, leaks and problems that may affect the free circulation of the solution through the hydraulic circuit.

\subsection{Spray Nozzle Inspection}

According to the type of nozzle, with the help of a protractor, the groove angle was evaluated; the maximum acceptable angle for each nozzle was $10^{\circ}$. Subsequently, the presence and functioning of anti-drip valves was observed; this item was considered appropriate when dripping ceased within a maximum time of 5 seconds after the end of spraying.

Flow evaluation was determined by the utilization of the sprayer's own pressurization system with the nozzles attached to the spray wand. A manometer was attached to the center of each section of the wand, in order to determine system pressure at all collection points. In order to determine nozzle flow, glass graduated cylinders were used, with volumetric capacity of $1 \mathrm{~L}$. Nozzles were considered approved when they did not exceed by $\pm 10 \%$ their own technical specifications for flow, for nozzles with flow greater than or equal to $1.0 \mathrm{~L} \mathrm{~min}^{-1}$, and by $\pm 15 \%$ for nozzles with flow lesser than $1.0 \mathrm{~L} \mathrm{~min}^{-1}$, considering the utilization of maximum pressure for each type of nozzle.

The transverse distribution of the nozzles attached to the wand was evaluated by means of a Hypro ${ }^{\circledR}$ nozzle patternator. Collectors allowing determination of transverse volume are composed of cylinders graduated at 1 $\mathrm{mL}$, with maximum capacity of $100 \mathrm{~mL}$. The evaluation of distribution was thus realized in three distinct points of the wand (left end, center and right end); the height of the wand was determined according to the recommendations of the nozzle manufacturers, under previous consultation of their User Guides. After collection, by calculating the coefficient of variation (CV), the distribution profile was evaluated; it was considered appropriate (up to $10 \%$ ) or inappropriate (greater than $10 \%$ ).

For the determination of nozzle flow and distribution profile, collection was realized during one minute, and the pressure used was determined in accordance with the type of nozzle attached to the wand. For flat fan spray nozzles, pressure was $285 \mathrm{kPa}$ (3.0 bar); for cone spray nozzles, pressure was $666 \mathrm{kPa}$ (7.0 bar). 


\subsection{Spray Pump Inspection}

The level of lubricating oil was determined, and the presence and type of agitator (whether mechanical or hydraulic) defined. Subsequently, the pump flow was determined with the help of a plastic container with volumetric capacity of $50 \mathrm{~L}$, and a graduated cylinder. When the flow differed from the flow stated by the manufacturer, tolerance for approval was $\pm 10 \%$.

Pump pressure pulsation was evaluated by removing the sprayer's manometer and replacing it with a high-precision manometer. The pressure used was $285 \mathrm{kPa}$ (3.0 bar); if there was variation in system pressure (pulsation), it should not exceed $\pm 10 \%$.

After this, the evaluation of system pressure drop was undertaken; it was determined by the use of analogical manometers attached to the end of each section of the wand. The maximum pressure recommended by spray nozzle manufacturers was used; a difference by $\pm 10 \%$ between the pressure close to the pump and the pressure at the end of each section was considered acceptable.

After measuring system pressure drop, pressure variation was determined for each of the closed sections. The sections were closed, one by one, and the pressure registered in the digital manometer of the sprayer should not exceed by $\pm 10 \%$ the pressure registered in all the functioning sections. This was regulated at $285 \mathrm{kPa}$ (3.0 bar) before the beginning of the procedure.

For the evaluation of pressure variation with spraying off, system pressure was regulated at 3.0 bar with all sections functioning; then, spraying was turned off; after ten seconds, the measurement of the sprayer manometer was taken. Difference should not exceed by $\pm 10 \%$ for approval.

For the evaluation of pressure distribution to each section of the sprayer, a high-precision manometer was attached to each end of the sections, adjusting spraying pressure to the maximum pressure informed by the nozzle manufacturer. Difference among manometers should not exceed by $\pm 10 \%$ for approval.

At the end of the evaluations, the inspection report was given to producers or to theirs representatives; it contained the data for the identification of the sprayer, its characteristics observed along the process, and its classification. The classification was done according to the index developed by PIPA, which classifies sprayers in accordance with their percentage of conformity to ISO 16122. Sprayers with an index greater than $90 \%$ were classified as conforming to the standard; between 89 and $70 \%$ as partially conforming to the standard; below $69 \%$, as non-conforming to the standard.

After evaluations were conducted, the data collected were submitted to exploratory analysis by descriptive statistics with the use of percentage frequency.

\section{Results and Discussion}

There were 56 inspections undertaken; $44.64 \%$ of the samples corresponded to sprayers attached to the traction bars of agricultural tractors, and $55.36 \%$ were sprayers attached to three points of the tractor.

\subsection{Tank Inspection}

When inspecting the presence of agrotoxic remains, it was observed that $85.71 \%$ of the sprayers were clean both inside the tank and outside (tank and structural components), which results are superior to Dornelles (2008), which displayed an approval rate of only $47.90 \%$ for this item. It was also observed that the closing lid was present in $100.00 \%$ of the sprayers; however, $5.36 \%$ were damaged, which prevented appropriate sealing (Table 1). This corroborates Casali (2012), in shows that the closure of the tank was approved in $95.70 \%$ of the samples. 
Table 1. Evaluation of the items composing the solution tank

\begin{tabular}{llll}
\hline Item & Good condition (\%) & Damaged (\%) & Absent (\%) \\
\hline Lid closure & 94.64 & 5.36 & - \\
Volume indicator & 75.00 & 17.86 & 7.14 \\
Product incorporator & 42.86 & 3.57 & 53.57 \\
Suction opening & 41.07 & 5.36 & 53.57 \\
Package pressure washing & 67.86 & 3.57 & 28.57 \\
Clean water for package washing & 28.57 & - & 71.43 \\
\hline & Present (\%) & Absent (\%) & Does not apply (\%) \\
\hline Pressure compensator & 26.79 & 66.07 & 7.14 \\
Non-return valve & 57.14 & 3.57 & 39.29 \\
\hline & Present (\%) & Absent (\%) \\
\hline Presence of product residues internally & 14.29 & \multicolumn{2}{c}{85.71} \\
Presence of product residues externally & 14.29 & \multicolumn{2}{c}{85.71} \\
Solution drain valve & 96.43 & \multicolumn{2}{c}{3.57} \\
\hline
\end{tabular}

The volume indicator was present in $92.86 \%$ of the sprayers; however, $17.86 \%$ were damaged or unreadable, which values are higher than those found by Dornelles (2008), which shows that only $56.00 \%$ of the sample presented volume indicator, and, in $5.95 \%$ of the indicators, the scale was either absent or unreadable.

The product incorporator was found to be absent in $53.57 \%$ of the sprayers. Dornelles (2008) attests a similar result: $33.30 \%$ of the sprayers were in conformity as to the presence of the incorporator. When the suction opening was present in the product incorporator, only $5.36 \%$ were found to be non-conforming to ISO 16122 (2015).

Package pressure washing was present in $71.43 \%$ of the sprayers; it was functional in $67.86 \%$ of the sprayers. It is important to note that, in most of the samples $(71.43 \%)$, pressure washing was done with the very content to be applied, which does not conform to current demands for package pressure washing, given that, in only $28.57 \%$ of the sprayers, the clean water tank was in good condition for use, which results corroborate those found by Dornelles (2008).

The pressure compensator, important for equalizing system pressure for sprayers using up to four pistons, was present in only $26.79 \%$ of the sprayers. It is important to note that, in $7.14 \%$ of the sprayers, piston and membrane pumps were used, which dispensed with the need for a pressure compensator, since there was an air chamber, the function of which was to reduce the negative effects resulting from phase alternation between admission and repression of the solution (Di Prinzio et al,. 2010).

It was also verified that, in $3.57 \%$ of the sprayers, there was no tank valve to drain the solution remaining from applications, which may be considered a problem, especially regarding the contamination of operators when washing the tank internally.

The non-return valve prevents the water to return to the tank during carriage; it was observed that, for $39.29 \%$ of the sprayers, this item did not apply, since carriage from the tank was by gravity, and did not use the sprayer carriage system. However, out of the $60.71 \%$ sprayers that used their own water carriage system, in $3.57 \%$, it was observed that the non-return valve was absent. According to Ramos \& Cortés (2006), the presence of a non-functional valve or its absence are considered serious, as they may occasion unwanted and hazarding effects to both the operator's health and to the environment.

\subsection{Manometer Inspection}

When manometers were inspected, it was observed that $96.43 \%$ of the sprayers had a manometer; however, $5.36 \%$ of the available manometers were not visible to the operator. The operating manometers were removed and submitted to bench-top evaluation, which enabled the measurement of their precision.

Legibility was considered adequate for $91.07 \%$, and the external diameter was according to standards in $87.50 \%$ of sprayers inspected (Table 2). 
Table 2. Approval of items for spray activation and manometer

\begin{tabular}{lll}
\hline Item & Approval (\%) & Rejection (\%) \\
\hline System pressure regulator valve & 92.86 & 7.14 \\
Spraying activation valve & 98.21 & 1.79 \\
Manometer (presence or absence) & 96.43 & 3.57 \\
Manometer (visibility to operator) & 94.64 & 5.36 \\
Manometer (legibility) & 91.07 & 8.93 \\
Manometer (external diameter) & 87.50 & 12.50 \\
Manometer (scale) & 75.00 & 25.00 \\
Glycerin level & 66.07 & 33.93 \\
Manometer (precision) & 35.71 & 64.29 \\
\hline
\end{tabular}

As for the scale used in the manometers, $75.00 \%$ were approved; on the other hand, in $33.93 \%$, glycerin levels were not in accordance to the standards.

The pressure valves and spraying valves were also evaluated. In $92.86 \%$, pressure valves demonstrated perfect functioning, which accords with what Dornelles (2008) describes for this item. Only $1.79 \%$ of the pressure valves were defective, not following the instructions of Standard ISO 16122.

The top-bench test showed that $64.29 \%$ of the manometers were rejected; among those considered functioning, the highest precision error was a display of $75.00 \%$ of the $571 \mathrm{kPa}(6.0 \mathrm{bar})$ pressure, when evaluated in both ascending and descending directions, corroborating the results obtained by Siqueira and Antuniassi (2011), which describe that the percentage of inappropriate manometers was high, which was also attested by Machado (2014). There were also non-functioning manometers, which, when top-bench tested, were "locked up", and did not inform hydraulic circuit pressure.

The data collected regarding manometers are reason for even greater concern when compared to those found in Dornelles et al. (2011), which shows that $30.1 \%$ of the manometers evaluated were damaged, and that, after evaluation of external diameter, glycerin levels and measurement precision, only $19.05 \%$ were approved. Nevertheless, during the second phase of the same project, when these sprayers were reevaluated, Casali (2012) attested improvements, raising approval rates by $15.75 \%$.

On the other hand, there were also observed problems regarding samples for manometer evaluations in studies conducted in Europe, where sprayer inspection is mandatory. According to Ramos \& Cortés (2006), only $20 \%$ of the manometers were approved after legibility, scale and pressure precision evaluations, in a study conducted at Escuela Politécnica Superior de Huesca [Polytechnic School of Huesca] e Universidad de Zaragoza [University of Zaragoza].

\subsection{Strainer Inspection}

Regarding strainer conservation, it was possible to observe that the main concern of producers is related to pump strainers, line strainers and nozzle strainers (Table 3), and these presented the highest approval rates when inspected.

Table 3. Classification of strainers (supply, tank, pump, line and nozzle), and representation of valve functioning for washing of strainer

\begin{tabular}{lllll}
\hline Item & Good condition (\%) & Damaged (\%) & Absent (\%) & Does not apply (\%) \\
\hline Supply strainer & 37.50 & 3.57 & 19.64 & 39.29 \\
Tank strainer & 78.57 & 10.71 & 10.72 & - \\
Pump strainer & 96.43 & - & 3.57 & - \\
Line strainer & 96.43 & - & 3.57 & - \\
Nozzle strainer & 94.64 & - & 5.36 & - \\
\hline \multicolumn{7}{l}{ Valve for strainer washing } & Good condition (\%) & Damaged (\%) & \\
\hline
\end{tabular}


Of the total, $39.29 \%$ of the sprayers inspected presented no water carriage system (as pointed earlier), and consequently had no supply strainer. The remainder presented this item, but in only $37.50 \%$ of the samples the supply strainer was in good condition; it was damaged in 3.57\%, and absent in $19.64 \%$. This must be highlighted, as the absence of strainers or their deterioration hinders their main role in the hydraulic circuit (Dornelles, 2008). However, it may be observed that almost all of the supply strainers present (35.71\%) were clean (Figure 1), thus allowing better system supply and higher quality spraying (Casali, 2012).

As for the tank strainer, it was present in $89.28 \%$ of the strainers; it was damaged in $10.71 \%$. Only $64.29 \%$ did not contain residues, as shown in Figure 1. The pump strainer was present in $96.43 \%$ of the strainers; $35.71 \%$ of them contained residues.

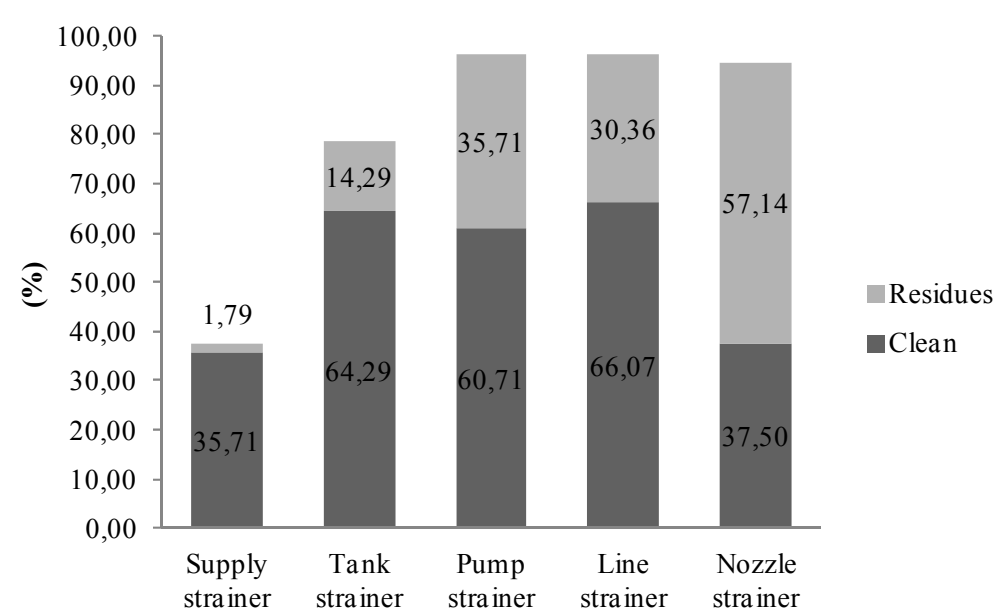

Figure 1. Sprayer distribution (clean and with residues for each item evaluated)

Regarding line strainers and nozzle strainers, it was observed that they were absent in, respectively $3.57 \%$ and $5.36 \%$ of the strainers (Table 3). Nevertheless, of the total amount that was deemed to be in good conditions, $30.36 \%$ contained residues, as Figure 1 shows. Similar results were obtained by Baldi and Vieri (1992), which observed that, in Italy, $36.00 \%$ of the inspected sprayers had no line strainer, were damaged, or contained residues.

The situation was worse for nozzle strainers: $57.14 \%$ of the samples contained residues. Residues were not the only reason for rejection; in $26.79 \%$, besides residues, it was also observed the use of distinct strainers, which may occasion problems in the nozzles (flow reduction and early wear), as well as in the distribution of the solution, since there is a difference in the number of meshes by square inch, thus affecting the efficiency of the straining system.

The valves for strainer washing were present and functioning in $85.71 \%$ of the inspected strainers; this enables the correct maintenance and cleaning of the straining system.

According to Ramos and Cortés (2006), the supply strainer was present in their entire sample, but pump strainers were present in $50.00 \%$ of the sprayers; line strainers presented a higher percentage $(70.00 \%)$; nozzle strainers were present in only $20.00 \%$ of their sample. Ramon and Cortés call attention to the fact that, in only $50.00 \%$ of the inspected equipment, strainers were clean and with no mesh wear. They consider that, out of the full sample, $40.00 \%$ presented dirty strainers, and $10.00 \%$ presented mesh wear; they further highlight that the position of the latter in sprayer structure makes cleaning and maintenance difficult.

\subsection{Spray Wand Inspection}

When inspecting the safety items in the spray wand, as may be seen in Table 4 , items related to height adjustment, damping and stabilization, as well as to the wand's safety system, were observed to have no defect in most sprayers, with approval rates of, respectively, $91.07 \%, 94.64 \%$, and $91.07 \%$. 
Table 4. Conformity percentage for items inspected in the spray wand

\begin{tabular}{|c|c|c|c|c|}
\hline Item & No defect (\%) & Slight (\%) & Serious (\%) & Absent (\%) \\
\hline Height adjustment & 91.07 & 3.57 & 1.79 & 3.57 \\
\hline \multirow[t]{2}{*}{ Damping and stabilization } & 94.64 & - & 3.57 & 1.79 \\
\hline & No defect (\%) & Slight (\%) & & Serious (\%) \\
\hline Stability & 82.14 & - & & 17.86 \\
\hline \multirow[t]{2}{*}{ Symmetry } & 50.00 & 10.71 & & 39.29 \\
\hline & No defect (\%) & Absent (\%) & & Does not apply (\%) \\
\hline Protection for external nozzles & 37.50 & 55.36 & & 7.14 \\
\hline Item & No defect (\%) & & Serious (\%) & \\
\hline Hose positioning & 66.07 & & 33.93 & \\
\hline Safety system & 91.07 & & 8.93 & \\
\hline Spacing between nozzles & 50.00 & & 50.00 & \\
\hline Uniformity of wand (vertical) & 89.29 & & 10.71 & \\
\hline Uniformity of wand (horizontal) & 60.71 & & 39.29 & \\
\hline
\end{tabular}

As for stability and symmetry, it was observed that, in $82.14 \%$ of the inspected strainers, wand stability presented no defect. However, when symmetry was concerned, in $50.00 \%$, there was some type of damage in the structure; $39.29 \%$ of the wands were classified as severely damaged, as they affected the quality of the application.

As for vertical and horizontal uniformity, it was observed that the most serious problems were related to horizontal uniformity (39.29\%), due mostly to wear of the structural components and links between sections, as well as by deformation, often occasioned by impact of the wand against obstacles. It was verified that, regarding vertical uniformity, $89.29 \%$ of the wands presented no defect, which may be justified by the use of appropriate and efficient damping and stabilization structures, dimensioned in accordance to the length of the wand.

As for spacing between nozzles, only $50.00 \%$ of the samples were in accordance with manufacturers' recommendations for the spray nozzles used; the mean error in the number of incorrect spaces was 3.12 by sprayer; this corroborates data presented by Gandolfo (2001), and is higher than data presented by Dornelles (2008), which study observed a mean error of 1.93 incorrect spaces by wand. As for the total spacing evaluated, it was possible to observe that $10.00 \%$ of them were wrong; the highest error was by $76 \%(0.12 \mathrm{~m}$ spacing using nozzles that would have to be spaced by $0.5 \mathrm{~m}$ ), which data is significantly superior to the $2.0 \%$ obtained by Langenaken and Pieters (1997), when inspecting spraying techniques in Belgium. It should be noted the high error rate in spacing between nozzles was observed mainly on equipment in which the wand had been adapted.

Errors in nozzle spacing affect negatively the distribution of the droplets generated by the nozzles, since the height of the wand is given by a ratio between the opening angle of the nozzle outpour and nozzle spacing along the wand. In this sense, when nozzle spacing is below manufacturer recommendations, there may be excess of deposits, leading to phytotoxicity in the culture. On the other hand, when spacing is superior to manufacturer recommendations, there may be lack of deposits in the target, which causes inefficiency in their control.

Regarding the safety structure for the wands' external nozzles in accordance to ISO 16122, this structure should be present in sprayers equipped with wands with length greater than $10 \mathrm{~m}$. Nonetheless, only $37.50 \%$ presented such protection; it should be noted that, for $7.14 \%$ of the sprayers evaluated, this item does not apply, given that their length was inferior to $10 \mathrm{~m}$.

Regarding hose positioning, it was observed that it was inadequate in $33.93 \%$ of the sprayers, resulting in twisted hydraulic circuit hoses, which may limit system pressure and obstruct the flow of the solution to be applied. Gandolfo (2001) observed errors in hose positioning in $60.50 \%$ of the study's samples.

These errors occasioned droplet deposition in structural components of the sprayers, causing the solution to drip, and thus affecting the biological target's coverage. Of the total amount of sprayers inspected, depositions in structural components reached 93 points. $97.85 \%$ of these were classified as dripping, and $2.15 \%$ as continuous leaking. These numbers are higher than those found by Huyghebaert et al. (1996), which study observed this type of problem in only $0.81 \%$ of the sprayers evaluated in Belgium.

In the evaluation of the spray wands composing the sprayers inspected, it was possible to verify that, in $26.79 \%$, the producers had replaced the original wand by longer ones, with an increase in the operational capacity. As a 
result, in some cases this affected stability negatively, which may be related to the use of differing structural projects, altering in particular the damping and stabilization systems of the wands. However, the main factor occasioning stability issues is the lack of maintenance of the hydraulic circuit composing the opening and closure system.

\subsection{Spray Nozzle Inspection}

Regarding the visual uniformity of the wands, it was possible to observe that, in some cases, the use of different nozzles resulted in a $10.71 \%$ rejection rate for the evaluated sets (Table 5).

Table 5. Approval for items related to sprayer nozzles

\begin{tabular}{llll}
\hline Item & Approval (\%) & \multicolumn{2}{c}{ Rejection (\%) } \\
\hline Visual uniformity & 89.29 & & 10.71 \\
Transverse Distribution & 26.79 & 73.21 & \\
Nozzle flow & 80.36 & 19.64 & \\
\hline & No defect (\%) & Serious (\%) & Absent (\%) \\
\hline Anti-drip valve & 73.21 & 16.08 & 10.71 \\
\hline & No defect (\%) & Serious (\%) & Does not apply (\%) \\
\hline Groove angle & 56.36 & 30.91 & 12.73 \\
\hline
\end{tabular}

When nozzle transverse distribution was evaluated, $73.21 \%$ of the sprayers were rejected. The main consequences of this high rejection rate for transverse distribution are related to the wearing and obstruction of nozzles, system pressure variation, errors in nozzle spacing, and errors in the groove angle of the nozzles. Machado (2014) observed that uniformity in distribution was rejected in $35.00 \%$ of the sprayers evaluated, which, according to the author, may be related to the uniformization of the nozzles used. Similarly, Silveira et al. (2006) showed that there were errors in the transverse distribution of the nozzles in $33.00 \%$ of the sprayers evaluated.

However, when evaluating flow, considering all the nozzles composing the spray wand, $80.36 \%$ were conforming to the standard. On the other hand, of the total amount of nozzles evaluated (1634), 14.20\% were damaged or obstructed, which represents an average in disagreement with the methodology employed of 4.14 nozzles by sprayer, which value is higher than the one found by Dornelles (2008), which had an average value of 3.3 inappropriate nozzles by sprayer.

Taking this evaluation into consideration, the most critical cases found were in two sprayers, where approximately $85.00 \%$ of the nozzles composing the wands were outside the maximum quantificational limits for approval of the nozzle set. According to Dornelles et al. (2009), the use of inappropriate, excessively worn nozzles, or of ill-calibrated sprayers are some of the factors contributing to environmental contamination and inefficiency in the applications.

The extremest results obtained were related to flow reduction by $100.00 \%$ (total flow obstruction) and higher than the specified flow (intense wear) by approximately $413.00 \%$. These numbers are superior to those obtained by Baldi and Vieri (1992), which study observes a variation of 19.5\% (obstruction and wear), which represented an average $\mathrm{CV}$ of $22.3 \%$.

After determining nozzle flow, the presence and functioning of the anti-drip valve was assessed. It was observed that if was absent in $10.71 \%$ of the sprayers, thus allowing waste of products and environmental contamination. In the $89.29 \%$ that presented anti-drip valves in the wand, $16.08 \%$ were not functional, thus allowing product loss after the end of spraying. Superior results were found by Siqueira and Antuniassi (2011): 39.70\% of the sprayers inspected presented problems in the anti-drip valve.

When evaluating the groove angle of the spray nozzles, it was possible to conclude that, in only $56.36 \%$ of those sprayers equipped with flat fan spray nozzles, the angle was within recommendations. Groove angle plays a major role in the transverse distribution of the droplets, and consequently in target coverage. When nozzle disposition is not in accordance with manufacturers' recommendations, there may occur a reduction in the deposition of the solution, and consequently a reduction in the efficiency of control; it may also provoke droplet attrition during their dislocation, thus forming larger drops, which may occasion phytotoxicity in the culture by concentration of the active ingredient in use. 
When nozzles are appropriately placed in the wand, the superposition of droplets occurs appropriately, avoiding their collision with one another. Droplet collision results in higher solution concentration in some points along the wand, affecting the uniformity of deposition (Antuniassi \& Boller, 2011).

\subsection{Spray Pump Inspection}

The items pertaining the evaluation of sprayer pumps and the diagnosis of sprayers' hydraulic circuit conditions are presented in Table 6 .

Table 6. Diagnosis of sprayer hydraulic circuit conditions

\begin{tabular}{|c|c|c|c|}
\hline Item & Approval (\%) & \multicolumn{2}{|c|}{ Rejection (\%) } \\
\hline Agitator & 100.00 & \multicolumn{2}{|c|}{-} \\
\hline System pressure pulsation & 94.64 & \multicolumn{2}{|c|}{5.36} \\
\hline End-of-section pressure drop & 89.29 & \multicolumn{2}{|c|}{10.71} \\
\hline Pressure variation with sections closed & 75.00 & \multicolumn{2}{|c|}{25.00} \\
\hline Pressure distribution & 85.71 & \multicolumn{2}{|c|}{14.29} \\
\hline Pressure variation with spraying turned off & 21.43 & \multicolumn{2}{|c|}{78.57} \\
\hline Pump flow & 76.79 & \multicolumn{2}{|c|}{23.21} \\
\hline & Inside $(\%)$ & Outside $(\%)$ & No level $(\%)$ \\
\hline Pump lubricanting oil level & 71.43 & 12.50 & 16.07 \\
\hline
\end{tabular}

This evaluation showed that $100 \%$ of the sprayers were approved as to the presence of the agitator. However, $69.64 \%$ of the sprayers presented only the hydraulic system as agitator, which entailed a return of the repressed amount by the spray pump; only $30.36 \%$ of the sprayers presented some type of mechanical hydraulic agitation (Figure 2).

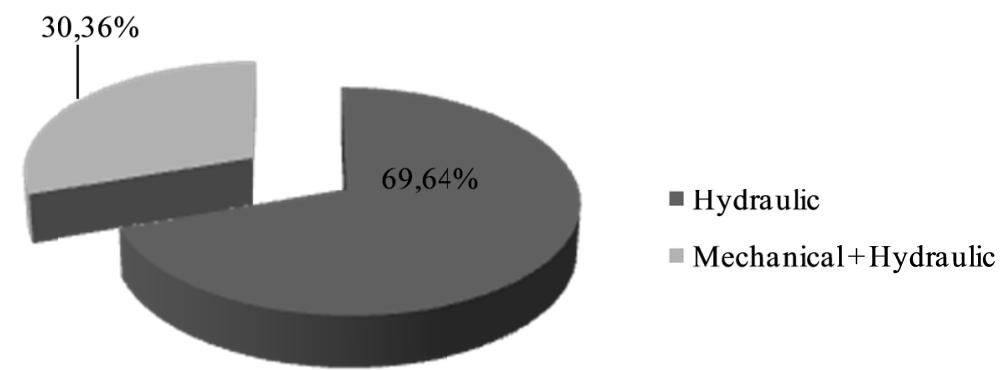

Figure 2. Category division referring to agitators present in the sprayers inspected

When evaluating spraying system pressure, it was observed that pressure pulsation was the item with the highest approval rates, and was found conforming in $94.64 \%$ of the sprayers. Pressure drop and distribution also presented good approval rates; $89.29 \%$ and $85.71 \%$ of the sprayers were approved as to end-of-session pressure drop and pressure distribution, respectively.

However, when pressure variation within closed sections was evaluated with the sprayer turned off, rejection rates went up; in $25.00 \%$ of the evaluations, pressure variation when the wand's sections were turned off (one by one) presented differences superior to the limits established by ISO 16122.

The most accentuated problem in this item was that, when evaluating pressure variation with the spraying turned off, only $21.43 \%$ of the sprayers met the recommendation described in the methodology. Adequacy on this head may be attributed to the presence of a pressure compensator valve, since it is necessary in hydraulic circuits that use pumps with up to four pistons for the adequate pressurization of the system. These results were attested by Di Prinzio et al. (2010), which explain that volumetric and semi-volumetric pumps provide irregular flow due to the alternation between solution admission and repression phases. This variation determines continuous shifts in pressure internal to the hydraulic circuit, and may cause negative effects. For this reason, the pressure compensator it uses, which consists of an air chamber normally separated from the hydraulic circuit by a membrane. 
It is also important to note that, only $7.14 \%$ of the sprayers used piston and membrane pumps, dispensing with the mandatory use of a pressure compensator, as presented in Table 1. However, it was observed that sprayers were also rejected for pressure variation with spraying turned off. Thus, when considering sprayers dispensing with pressure compensator valves and those in which they were absent, the final result was that $73.21 \%$ of the sprayers met the requirements set by ISO 16122 (Table 1).

When pump flow was evaluated, $76.79 \%$ of the pumps presented the flow described by the manufacturer in their nominal rotation rate. Furthermore, lubricant oil levels were evaluated: in $16.07 \%$, the level indicator was absent; in $12.50 \%$, oil levels were not in accordance to the manufacturers' technical specifications.

Based on the results obtained, it may be attested that, of the 56 sprayers evaluated, $67.86 \%$ were classified as non-conforming to the standard; $26.79 \%$ were classified as partially conforming; only $5.36 \%$ were classified as conforming to the Standard ISO 16122.

\section{Conclusion}

After the analysis of the results obtained, it may be concluded that there is need for agricultural sprayer inspections to be mandatory in Brazil; it is also necessary to appoint research centers for the realization of this type of inspection, as well as to invest on government policies that promote financial incentives to the primary sector, especially regarding the modernization of agricultural fleet.

Considering the most frequent application problems, it was possible to verify that, in $64.29 \%$ of the evaluations, the precision of the manometer was considered seriously flawed; in $73.21 \%$, the transverse distribution of the spraying wand was also seriously flawed, which is related principally to errors in the space among spray nozzles, and to their wear, affecting $76.79 \%$ of the cases in terms of application volume. Besides these, it was also observed that, in $69.64 \%$ of the inspected sprayers, the PTO rotation was below recommendation.

Regarding the applicability of Standard ISO 16122, it was concluded that it presents in a clear and practical manner the methodology to be used in the inspection of sprayers attached to the hydraulic system in three points, or to the traction bar of a tractor. However, in the Brazilian market, self-propelled sprayers are used, which employ several electronic devices, Standard ISO 16122 needs to be updated in this sense, so as to include methodology specific to the inspection of this type of equipment. Taking this into account, in case it be transcribed as ABNT NBR ISO 16122, the latter must specify new parameters so it be unanimously and appropriately used in accordance to Brazilian reality.

\section{References}

Antuniassi, U. R., \& Boller, W. (2011). Tecnologia de aplicação para culturas anuais. Passo Fundo: Aldeia Norte.

Baldi, F., \& Vieri, M. (1992). Controllo e certificazione delle machine per la distribuzione dei fitofarmaci. Macchine per la Distribuzione de Fitofarmaci, 38, 17-32.

Casali, A. L. (2012). Condições de uso de pulverizadores e tratores na região central do Rio Grande do Sul (Master's thesis, Universidade Federal de Santa Maria, Santa Maria, Brazil). Retrieved from http://w3.ufsm.br/ppgea/index.php/publicacoes/dissertacoes

Declercq, J., Huyghebaert, B., \& Nuyttens, D. (2009). An overview of the defects on tested field sprayers in Belgium. 3rd European Workshop on Standardised Procedure for the Inspection of Sprayers (pp. 157-163). Brno, Czech Republic.

Di Prinzio, A., Behmer, S., \& Magdalena, J. C. (2010). Equipos pulverizadores terrestres. In J. C. Magdalena, B. C. Herrán, D. Prinzio, I. H. A., Bannister, \& J. Villalba (Eds.), Tecnología de aplicación de agroquímicos (pp. 107-120). Rio Negro, Argentine.

Dornelles, M. E. de Carvalho. (2008). Inspeção técnica de pulverizadores agrícolas no Rio Grande do Sul (Master's thesis, Universidade Federal de Santa Maria, Santa Maria, Brazil). Retrieved from http://w3.ufsm.br/ppgea/index.php/publicacoes/dissertacoes

Dornelles, M. E., Schlosser, J. F., Casali, A. L., \& Brondani, L. B. (2009). Technical inspection of agricultural sprayers: historic and importance. Ciência Rural, 39(5), 1601-1606. https://doi.org/10.1590/S0103-8478200 9005000133

Dornelles, M. E., Schlosser, J. F., Boller, W., Russini, A., \& Casali, A. L. (2011). Technical inspection of tractors and sprayers used in agricultural spraying. Engenharia na Agricultura, 19(1), 36-43. https://doi.org/ 10.13083/reveng.v19i1.222 
Gandolfo, M. A. (2001). Inspeção periódica de pulverizadores agrícolas (Doctoral dissertation, Universidade Estadual Paulista Júlio de Mesquita Filho, Botucatu, Brazil). Retrieved from https://repositorio.unesp.br/ handle/11449/101752

Ganzelmeier, H. (2007). Rules of approval, rules of inspection, quality management of inspection in Germany. 2nd European Workshop on Standardized Procedure for the Inspection of Sprayers in Europe (pp. 29-33). Straelen, Germany.

Huyghebaert, B., Mostade, O., Carre, J., \& Debouche, C. (1996). Compulsory inspection of crop sprayers already in use Belgium: Selection of control method. AgEng Madrid, 96(26), 79-86.

ISO. International Organization for Standardization. (2015). ISO 16122: Agricultural and forestry machinery-Inspection of sprayers in use. Geneva.

Koch, H. (1996). Periodic inspection of air-assisted sprayers. Bulletin OEPP/EPPO Bulletin, 26(1), 79-86. https://doi.org/10.1111/j.1365-2338.1996.tb01531.x

Lanças, K. P., \& Antuniassi, U. R. (1998). Manutenção dá vida longa ao trator. A Granja, 54(8), 40-50.

Langenakens, J., \& Pieters, M. (1997). The organization and first results of the mandatory inspection of crop sprayers in Belgium. Optimizing Pesticide Application, 48, 233-240.

Machado, T. M. (2014). Periodic inspection of boom sprayers in the region of Guarapuava-PR. Enciclopédia Biosfera, 10(19), 1225-1233.

Martini, A. T., Avila, L. A., Camargo, E. R., Helgueira, D. B., Bastiani, M. O., \& Loeck, A. E. (2016a). Pesticide drift from aircraft applications with conical nozzles and electrostatic system. Ciência Rural, 46(9), 1678-1682. https://doi.org/10.1590/0103-8478cr20151386

Martini, A. T., Schlosser, J. F., Farias, M. S., Oliveira, L. F. V., \& Herzog, D. (2016b). Mesmos erros. Cultivar Máquinas, 163(14), 16-19.

Osteroth, H. J. (2004). Inspection of sprayers in Germany-Results and experience over the past decades. First European Workshop on Standardized Procedure for the Inspection of Sprayers in Europe (pp. 68-73). Braunschweig, Germany.

Ramos, F. J. G., \& Cortés, M. V. (2006). Inspección técnica de equipos para la aplicación de fitosanitarios. Vida Rural, 227, 38-42.

Siqueira, J. L., \& Antuniassi, U. R. (2011). Periodic inspection of sprayers on soybean production areas in Brasil. Revista Energia na Agricultura, 26(4), 92-100. https://doi.org/10.17224/EnergAgric.2011v26n4p92-100

\section{Appendix A}

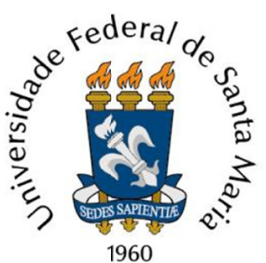

Proprietor:

\section{AGRICULTURAL SPRAYER INSPECTION \\ PROJECT \\ LABORATÓRIO DE \\ AGROTECNOLOGIA-AGROTEC/UFSM}

City:
Date: I_ I_ Sprayer $n^{0}:$

Model:

Year of acquisition:

Cultivation:

Number of sessions:

Nozzle in use:

Model:

Sprayer $n^{\circ}$

Tank:

Brand:

(L) Year of manufacture: GPS point:

Lenght boom: (m) Hours/Year: Tractor: Number of nozzles: Coupling: Year of manufactura: Hours of use: 


\section{Tank}

Presence of product residues internally:

Presence of product residues externally:

Lid closure:

Volume indicator:

Product incorporator:

Suction opening:

Package pressure washing:

Pressure compensator:

Solution drain valve:

Non-return valve:

Clean water for package washing:

( $\quad$ ) Present
( $\quad$ ) Present
( $\quad$ ) Good condition
( $\quad$ ) Good condition
$(\quad)$ Good condition
$(\quad)$ Good condition
$(\quad)$ Good condition
$(\quad)$ Present
$(\quad)$ Present
$(\quad)$ Present
$(\quad)$ Good condition

\section{Manometer}

Type:

Visibility to operator:

Glycerin level:

Scale:

Legibility:

( $\quad$ ) Analog
( $\quad$ ) Approval
( $\quad$ ) 0
( $\quad$ ) Approval
( $\quad$ Approval

Pressure used ( ) External diameter?

System pressure regulator valve:

Spraying activation valve:

\section{( ) Approval}

( ) Approval

$\begin{array}{ll}(\quad) \text { Absent } & \\ (\text { ) Absent } & \\ (\quad) \text { Damaged } \quad(\quad) \text { Absent } \\ (\quad) \text { Damaged } \quad(\quad) \text { Absent } \\ (\quad) \text { Damaged } \quad(\quad) \text { Absent } \\ (\quad) \text { Damaged } \quad(\quad) \text { Absent } \\ (\quad) \text { Damaged } \quad(\quad) \text { Absent } \\ (\quad) \text { Absent } \quad(\quad) \text { Does not apply } \\ (\quad) \text { Absent } \\ (\quad) \text { Absent } \quad(\quad) \text { Does not apply } \\ (\quad) \text { Damaged } \quad(\quad) \text { Absent }\end{array}$

\subsection{Top Bench}

Precision: ( ) Approval ( ) Rejection

\begin{tabular}{|c|c|c|c|c|}
\hline \multirow{2}{*}{ Pressure bar-Precision gauge } & \multicolumn{2}{|c|}{ Ascending } & \multicolumn{2}{|c|}{ Decreasing } \\
\hline & Pressure bar & Error (\%) & Pressure bar & Error (\%) \\
\hline \multicolumn{5}{|l|}{1} \\
\hline \multicolumn{5}{|l|}{2} \\
\hline \multicolumn{5}{|l|}{3} \\
\hline \multicolumn{5}{|l|}{4} \\
\hline \multicolumn{5}{|l|}{5} \\
\hline \multicolumn{5}{|l|}{6} \\
\hline \multicolumn{5}{|l|}{7} \\
\hline \multicolumn{5}{|l|}{8} \\
\hline \multicolumn{5}{|l|}{9} \\
\hline \multicolumn{5}{|l|}{10} \\
\hline \multicolumn{5}{|l|}{11} \\
\hline \multicolumn{5}{|l|}{12} \\
\hline 13 & & & & \\
\hline
\end{tabular}




\begin{tabular}{|l|l|l|l|l|}
\hline 14 & & & & \\
\hline 15 & & & & \\
\hline 16 & & & & \\
\hline 17 & & & & \\
\hline 18 & & & & \\
\hline 19 & & & & \\
\hline 20 & & & & \\
\hline Average error (\%) & & & Average error (\%) & \\
\hline Total error (\%) & & & \\
\hline
\end{tabular}

\section{Conservation of Filters}

\begin{tabular}{|c|c|c|c|c|c|c|c|}
\hline Supply strainer: & $\begin{array}{l}(\text { ) } \\
(\end{array}$ & $\begin{array}{l}\text { Good condition } \\
\text { ) Does not apply }\end{array}$ & ( & ) Damaged & ( ) Absent & ( ) Clean & ( ) Waste \\
\hline Tank strainer: & ( & ) Good condition & ( & ) Damaged & ) Absent & ) Clean & ) Waste \\
\hline Pump strainer: & ( & ) Good condition & ( & ) Damaged & ) Absent & ) Clean & ) Waste \\
\hline \multirow[t]{7}{*}{ Line strainer: } & 1( & ) Good condition & ( & ) Damaged & ) Absent & ) Clean & ) Waste \\
\hline & 2( & ) Good condition & ( & ) Damaged & ) Absent & ) Clean & ) Waste \\
\hline & 3( & ) Good condition & ( & ) Damaged & ) Absent & ) Clean & ) Waste \\
\hline & 4( & ) Good condition & ( & ) Damaged & ) Absent & ) Clean & ) Waste \\
\hline & 5( & ) Good condition & ( & ) Damaged & ) Absent & ) Clean & ) Waste \\
\hline & 6( & ) Good condition & ( & ) Damaged & ) Absent & ) Clean & ) Waste \\
\hline & 7( & ) Good condition & ( & ) Damaged & ) Absent & ) Clean & ) Waste \\
\hline Nozzle strainer: & ( & ) Good condition & & ) Damaged & ) Absent & ) Clean & ) Waste \\
\hline \multicolumn{3}{|c|}{ Valve for strainer washing: } & ( & ) Good condition & ) Damaged & & \\
\hline
\end{tabular}

\section{Wand}

Stability:

Symmetry:

Hose positioning:

Safety system:

Spacing between nozzles:

\begin{tabular}{|c|c|c|}
\hline ) No defect & ( & ) Slight \\
\hline ) No defect & ( & ) Slight \\
\hline ) No defect & ( & ) Serious \\
\hline ) No defect & & ) Serious \\
\hline ) No defect & & ) Serio \\
\hline
\end{tabular}

Uniformity of wand:

\begin{tabular}{|c|c|c|c|c|c|c|}
\hline \multirow{2}{*}{ Vertical (cm): } & Left height: & \multicolumn{3}{|c|}{ Center height: } & \multirow{2}{*}{\multicolumn{2}{|c|}{ Right height: }} \\
\hline & ( ) No defect & ) Serious & & & & \\
\hline \multirow[t]{2}{*}{ Horizontal (cm): } & Left: & Right: & & & & \\
\hline & ( ) No defect & ( ) Serious & & & & \\
\hline Protection for external nozzle & & ) No defect & ( & ) Absent & ( & ) Does not apply \\
\hline Height adjustment: & ) No defect & ) Slight & ( & ) Serious & ( & ) Absent \\
\hline Damping and stabilization: & ) No defect & ) Slight & ( & ) Serious & ( & ) Absent \\
\hline
\end{tabular}




\section{Nozzles}

Visual uniformity:

Anti-drip valve:

Groove angle:

Transverse distribution:

Nozzle flow:

6. Pump

Agitator:

Type:

System pressure pulsation:

$$
\begin{aligned}
& \text { ( } \quad \text { ) Approval } \\
& \text { ( } \quad \text { ) No defect } \\
& \text { ( } \quad \text { ) No defect } \\
& \text { ( } \quad \text { Approval } \\
& \text { ( } \quad \text { Approval }
\end{aligned}
$$

Nominal Flow

(L/min)

( ) Approval

( ) Approval

( ) Hydraulic

( ) Approval
( ) Rejection

( ) Serious

( ) Serious

( ) Rejection

( ) Rejection

\section{( ) Serious \\ ( ) Does not apply}

\begin{tabular}{|l|l|l|l|l|}
\hline Pressure (Bar) & Minimum Reading & Difference (\%) & Maximum Reading & Difference (\%) \\
\hline & & & & \\
\hline Avarage Difference (\%) & & & \\
\hline
\end{tabular}

Lubricating oil: ( ) Inside ( ) Outside （） No Level （）Last Exchange (hs)

End-of-section pressure drop: ( ) Approval （ ) Rejection

\begin{tabular}{|l|l|l|l|}
\hline Section & Maximum nozzle pressure (Bar) & Pressure at the end of the section & Difference (\%) \\
\hline 01 & & & \\
\hline 02 & & & \\
\hline 03 & & & \\
\hline 04 & & & \\
\hline 05 & & & \\
\hline 06 & 07 & Avarage Difference (\%) & \\
\hline
\end{tabular}

Pressure variation with sections closed: $\quad(\quad)$ Approval $\quad(\quad$ ) Rejection

\begin{tabular}{|l|l|l|l|}
\hline Section & Pressure (Bar) & Pressure tem seconds after closing section & Difference (\%) \\
\hline 01 & 3 & & \\
\hline 02 & 3 & & \\
\hline 03 & 3 & & \\
\hline 04 & 3 & & \\
\hline 05 & 3 & & \\
\hline 06 & 3 & & \\
\hline 07 & 3 & & \\
\hline Avarage Difference (\%) &
\end{tabular}


Pressure variation with spraying turned off: $\quad(\quad)$ Approval $\quad(\quad)$ Rejection

\begin{tabular}{|l|l|l|}
\hline Pressure (Bar) & Pressure tem seconds after closing section & Difference (\%) \\
\hline & & \\
\hline
\end{tabular}

Pressure distribution: ( ) Approval ( ) Rejection

\begin{tabular}{|l|l|l|l|l|l|}
\hline Section & $\begin{array}{l}\text { Maximum } \\
\text { nozzle pressure } \\
\text { (Bar) }\end{array}$ & $\begin{array}{l}\text { Pressure at the } \\
\text { beginning of } \\
\text { the section }\end{array}$ & Difference (\%) & $\begin{array}{l}\text { Pressure at the } \\
\text { end of the } \\
\text { section }\end{array}$ & Difference (\%) \\
\hline 01 & & & & & \\
\hline 02 & & & & & \\
\hline 03 & & & & & \\
\hline 05 & & & & & \\
\hline 07 & & & & & \\
\hline Avarage Difference (\%) & & & & & \\
\hline \multicolumn{2}{|l}{ Total Difference (\%) } & & & & \\
\hline
\end{tabular}

\section{Copyrights}

Copyright for this article is retained by the author(s), with first publication rights granted to the journal.

This is an open-access article distributed under the terms and conditions of the Creative Commons Attribution license (http://creativecommons.org/licenses/by/4.0/). 